\title{
Arrangement of the Learning Process within the Framework of Stereometric Topics of Mathematics Based on Dynamic Applets
}

\author{
L. A. Gorovenko*, G. A. Aleksanyan, O. P. Rovenskaya \\ Armavir Mechanic-Technological Institute (Branch) of the Kuban State Technological University, Armavir, Russia \\ ${ }^{*}$ Corresponding author.Email: lgorovenko@mail.ru
}

\begin{abstract}
This article discusses the capabilities of dynamic applets in the study of stereometric topics of mathematics, provides an example of images of second-order surfaces and interactions with constructed drawings, as well as integration of dynamic applets into both distance learning and classroom learning. The article also discusses the introduction of technical means into the educational process, talks about the relevance of distance education, highlights the factors that determine the demand for use of technical means in the educational process.
\end{abstract}

Keywords: GeoGebra, stereometry, virtual office, distance learning, information educational environment, educational process.

\section{INTRODUCTION}

Since emerging the information technology, a lot of works have been written about the transition to the automation of learning, methods and specific examples of integration into the real educational process have been developed, but, nevertheless, there was no full reflection in the real educational process [1]. However, the coronavirus pandemic that began in 2019 not only launched the digital transformation of the educational process at all its levels, but also stimulated its development at a much faster pace than it was planned in the framework of various national projects, and also allowed teachers and administration of educational institutions to consider new methods of automating the educational process, as well as introduction of previously unexplored software products into the educational process, or use of already proven information products in a different way, expanding their capabilities in the field of education $[2,3]$.

It is obvious that the new format of education provides a wide range of opportunities and prospects for changing and improving those educational systems for which a critical situation creates forced conditions. First of all, we are talking about arrangement of an information and educational environment, which would make it possible to effectively implement all the educational functions of the learning process in a distance format $[1,4,5]$.

\section{STATEMENT OF THE PROBLEM AND DESCRIPTION OF METHODS FOR ITS SOLUTION}

Spatial geometry, in contrast to geometry on a plane, often causes students to have very serious difficulties in understanding. Flat geometric figures are studied even in the sections of school mathematics of the elementary and middle grades, they are easy to depict on a plane, with the same ease they can be imagined, which cannot be said about spatial figures. In this regard, the process of teaching the construction of stereometric figures in mathematics and the subsequent solution of problems about three-dimensional space is associated with certain difficulties.

On the one hand, individual listeners have insufficiently developed spatial perception of figures. So, it is difficult for them to imagine the relative position of points, lines, planes in space, the ratio of their individual parts and elements. All this entails a misunderstanding not only of certain topics of stereometry, but also a misunderstanding of the whole stereometry, as a branch of mathematics, as a whole. As a result, the student is unable to solve certain problems in this area or experiences serious difficulties in this. 
In addition, the teacher is faced with another problem: construction of three-dimensional figures, which are objects of stereometry, must be performed in two-dimensional space, i.e. on a plane (in a notebook, or on a student board). This factor adds uncertainty to an already difficult topic for perception. And this, in turn, significantly increases the likelihood that some of the students will master the educational material much worse, or will not understand it at all.

Obviously, some other tools for studying stereometry are necessary to solve these problems. We believe that use of 3D graphics services in classes related to the study of figures in space would be an excellent solution not only to these problems, but also to a number of other difficulties associated with teaching stereometry in higher education.

The following two types of computer technologies can be considered as such a toolkit:

1. Specialized software packages for 3D modeling;

2. Cloud technologies, through which the ability to provide constructed models for group use for educational purposes in mathematics classes can be implemented.

The constructed three-dimensional model of the problem makes it possible to ideally visualize not only the outlines of the figures, but also their relative position in space relative to each other. Therefore, we get rid of one of the problems described - the difficulty with the idea of how the figures shall be located and what their relative position is.

However, when using specialized software for constructing three-dimensional models, another problem arises - the user's lack of experience and knowledge in using the tools of this software. As a rule, in order to teach the entire audience to use this toolkit, it will take several introductory lectures, which is not always convenient and, often, does not correspond to the working programs of the studied disciplines. An obvious conclusion offers itself - if the teacher himself/herself knowns this toolkit, and if the constructed model can be integrated into the educational process without additional training for other users, then we would get an ideal model for presenting educational information within the framework of stereometric topics of mathematics, which would significantly increase visibility training material and at the same time would not require an increase in time resources for the study of these topics.

The next stage involves finding a way to ensure the accessibility of the constructed stereometric model to a wide audience of course participants. One of the ways to solve this problem is use of cloud services that support construction of figures in a virtual three-dimensional space. Such a solution in the study of stereometry has a lot of advantages, among which, first of all, it is worth highlighting such as:

- $\quad$ availability for use. It is provided by the ability to access the Internet via a link to a cloud resource;

- $\quad$ ensuring the visibility of the educational material presentation. It is carried out due to the functions of mobile control of the constructed model: it can be rotated, viewing it from different angles on the screen of your gadget, by controlling the joystick, mouse, or other tools intended for this;

- $\quad$ support of feedback between participants in the educational process. It is provided through the functions of group communication of cloud services. Wherein, this form of feedback is acceptable both when conducting classes with students in full-time format, and in classes in distance and part-time forms of education.

\section{CONSTRUCTION AND IMPLEMENTATION OF THE MODEL}

There are many software products for modeling and studying three-dimensional figures, but one of the leaders in this area is the GeoGebra cross-platform application, which can be installed on any device running any modern operating system, from desktop solutions to mobile phones, and launching the application directly in the browser.

Let's consider the implementation of modeling and use of three-dimensional objects in the study of one of the most difficult topics for students to perceive "Second Degree Surfaces". The complexity in the study of the topic lies in the fact that it is required to construct a set of three-dimensional figures, study them with varying parameter values and the possibility of viewing these figures from different angles of view. Obviously, it is very difficult to depict high-quality threedimensional figures on a plane (classroom board, virtual board, notebook or sheet of paper), and this process is time-consuming, while it is almost impossible to show changes in these figures when changing their parameters. Therefore, to arrange a high-quality process of studying this topic, you can use the GeoGebra application.

When launched, the program will offer several options for environments for further construction of spatial figures (Fig. 1).

From the offered options, select the "3D Graphics" tab, after which a three-dimensional Cartesian coordinate system with three coordinate axes will appear: OX, OY, OZ. This field, including the coordinate axes, can be customized to your liking (for example, you can select a unit interval or the directions and positions of the coordinate axes, as well as the scale and other settings). 
In new versions of the program, when you enter an equation using parameters, parameters are added automatically in the form of sliders to change the value of each of the parameters.

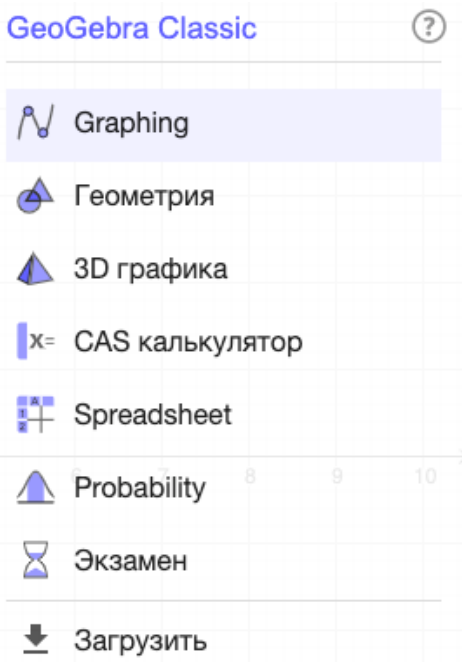

Figure 1 Environment options for object modeling

For example, to construct an ellipsoid, it is enough to enter the equation specifying the given surface in the advising field, while the values of variables and parameters can be typed both from the mechanical keyboard of the computer, and from the virtual keyboard of the program, which has much more advanced capabilities (Fig. 2).

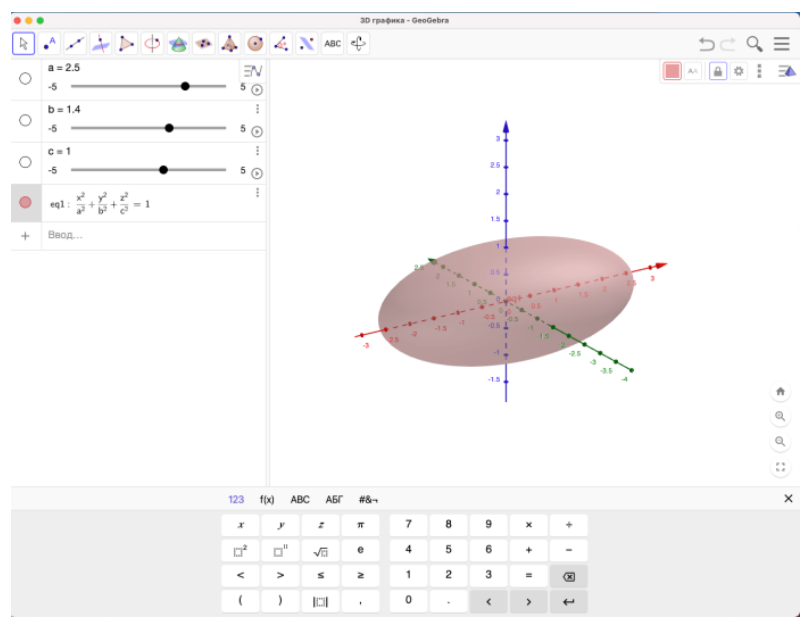

Figure 2 Ellipsoid image

In addition to constructing the main surfaces of the second order: an ellipsoid, a hyperboloid, a paraboloid, a cone, a cylinder, you can also consider the study of the canonical equations of each of the figures and observe in real time how the figure looks when changing specific parameters, and it is also possible to give this material in an interactive form, so that students independently come to advising conclusions, formalizing this study in the form of independent consideration and study. For example, when studying the canonical equation of a one-sheet hyperboloid, it is necessary to consider three sections by planes:

1) Section by planes $x=h$, then the equation will take the form (Fig. 3):

$$
\left\{\begin{array}{c}
\frac{x^{2}}{a^{2}}+\frac{y^{2}}{b^{2}}-\frac{z^{2}}{c^{2}}=1 \\
x=h
\end{array} \Rightarrow \frac{y^{2}}{b^{2}}-\frac{z^{2}}{c^{2}}=1-\frac{h^{2}}{a^{2}} ;\right.
$$

This equation defines:

a) for $|h|<a$ - hyperbola, with real axis $\| O y$;

b) for $|h|=a$ - hyperbola, with real axis $\| O z$;

c) for $|h|>a-$ a pair of straight lines.

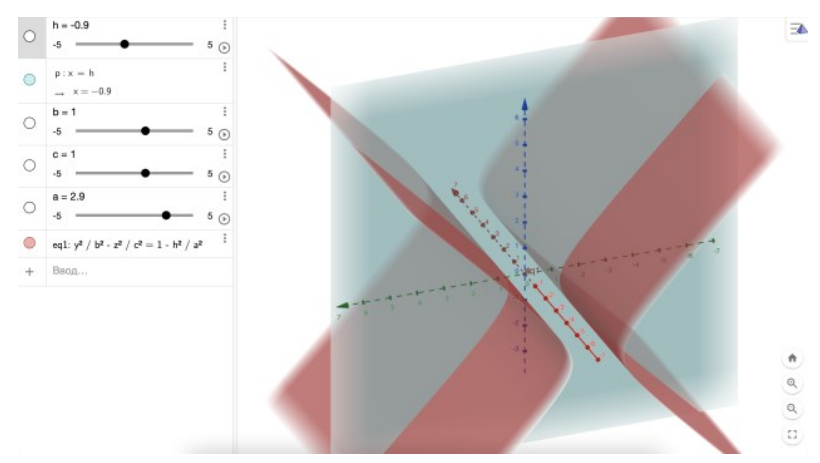

Figure 3 Section by planes $\mathrm{x}=\mathrm{h}$ of a one-sheet hyperboloid

2) Section by planes $y=h$, then the equation will take the form (Fig. 4):

$$
\left\{\begin{array}{c}
\frac{x^{2}}{a^{2}}+\frac{y^{2}}{b^{2}}-\frac{z^{2}}{c^{2}}=1 \\
y=h
\end{array} \Rightarrow \frac{x^{2}}{a^{2}}-\frac{z^{2}}{c^{2}}=1-\frac{h^{2}}{b^{2}} ;\right.
$$

This equation defines:

a) for $|h|<b$ - hyperbola, with real axis $\| O x$;

b) for $|h|=b$ - hyperbola, with real axis $\| O z$;

c) for $|h|>b-$ a pair of straight lines.

3) Section by planes $z=h$, then the equation will take the form (Fig. 5):

$$
\left\{\begin{array}{c}
\frac{x^{2}}{a^{2}}+\frac{y^{2}}{b^{2}}-\frac{z^{2}}{c^{2}}=1 \Rightarrow \frac{x^{2}}{a^{2}}-\frac{z^{2}}{c^{2}}=1-\frac{h^{2}}{b^{2}}
\end{array}\right.
$$

This equation defines an ellipse for any $h$. For $h=0$, the semiaxes of the ellipse will be the smallest. This ellipse is called the throat ellipse of a one-sheet hyperboloid.

Each of the examples considered above has the ability to change all the parameters included in the equations, which allows you to see the figure images in real time for each of the section and parameter options, which is difficult when using conventional drawing tools. 


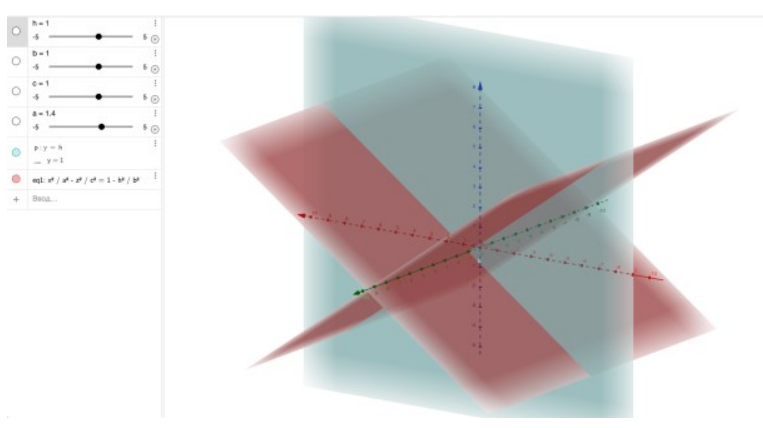

Figure 4 Section by planes $y=h$ of one cavity hyperboloid

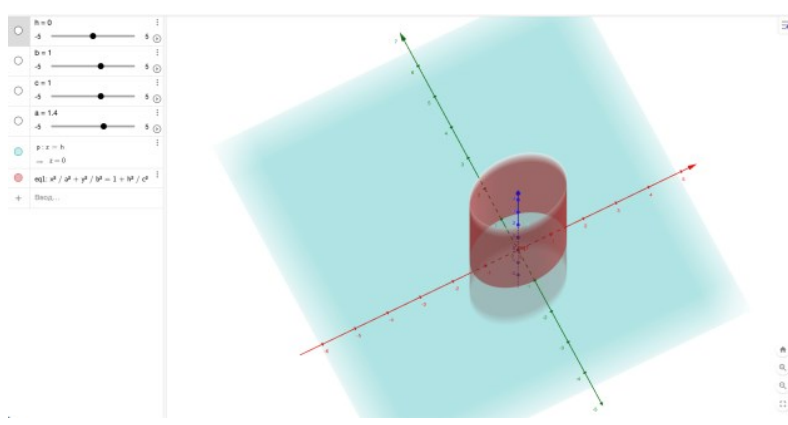

Figure 5 Section by planes $\mathrm{z}=\mathrm{h}$ of one-sheet hyperboloid

In a similar way, it is possible to consider all the figures of stereometry, while changing the parameters of the equation, as well as changing the angles of figures and sizes, all geometric properties are preserved.

Ready-made applets can be grouped by topic, or in any other way on the website of the educational institution or on the teacher's personal page, as well as in the personal account provided by the GeoGebra software environment itself, thereby arranging an educational environment with allowed access to groups of students (Fig. 6). The program allows to create applets for students with tasks, the implementation of which will allow to assess the quality of the learned material, as well as the level of proficiency in computer technology, which in modern society is one of the most demanded competencies of specialists [6-8].

\section{CONCLUSIONS}

Construction of virtual stereometric models for solving spatial problems by means of media services significantly increases assimilation of educational material. This is due to the fact that understanding of spatial images and the relative position of figures is greatly facilitated if there is a possibility of their "review from different angles" in real time and there is a possibility of observing changes in the outlines of figures when varying the parameters of their analytical expressions.

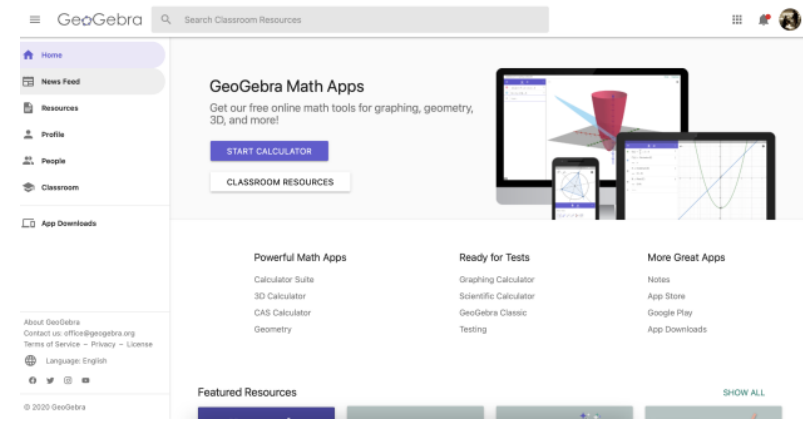

Figure 6 Personal account of the GeoGebra software environment

Ready-made models in the form of applets can be used in the educational process both in full-time education and within implementation of distance learning, which in the new epidemiological situation is a very significant factor in the successful mastering of educational material.

Practice shows that integration of technical means into distance learning changes the ways, methods and means of the educational process, contributes to intensification of the educational process, improves information resource support, and is a prerequisite for development of a qualitatively new teaching methodology. However, the teacher will always play a major role in both traditional and distance learning. The success of introduction of technical means into training fundamentally depends on the teacher qualifications.

\section{AUTHOR'S CONTRIBUTION}

The authors have developed a new model for implementation of the learning process on the topic of stereometry within the framework of the Mathematics discipline study. They also discussed the results and contributed to the final manuscript.

\section{ACKNOWLEDGMENTS}

The authors are very grateful to the referees for their valuable contributions to finalization of this study paper.

\section{REFERENCES}

[1] L.A. Gorovenko, O.P. Olkhovik, A.V. Pavrozin, S.V. Stadnik, Information Educational Environment Of A Technical Higher Educational Institution. In: International Journal of Engineering and Technology(UAE), 7(4.38) (2018) pp. 16081611.

[2] L.A. Gorovenko, G.A. Aleksanyan, Arrangement of distance learning using Internet technologies. In: Bulletin of the Adyghe State University, series 4: Natural-Mathematical and Technical Sciences, pp. 220-225. 
[3] I.F. Rahmadi, Teachers' Technology Integration And Distance Learning Adoption Amidst The Covid-19 Crisis: A Reflection For The Optimistic Future. In: Turkish Online Journal of Distance Education, 22(2) (2021) pp. 26-41.

[4] J.S.C. Hsu, H.H. Huang, L.P. Linden, ComputerMediated Counter-Arguments And Individual Learning. In: Educational Technology and Society, 14(4) (2011) pp. 111-123.

[5] T.A. Bekele, Motivation And Satisfaction In Internet-Supported Learning Environments: A Review. In: Educational Technology and Society, 13(2) (2010) pp. 116-127.

[6] G.A. Aleksanyan, Formation Of Independent Activity Of Secondary Vocational Education Students In Teaching Mathematics Using Cloud Technologies. In: extended abstract of dissertation ... of PhD in Pedagogy / Yelets. state un-ty named after I.A. Bunin. Yelets (2014).

[7] G.R. Antropova, S.N. Matveev, R.G. Shakirov. From The Practice Of Using Software Products In Solving Mathematical Problems. In: Bulletin of Naberezhnye Chelny State Pedagogical University, S2(31) (2021) pp. 63-67.

[8] G.A. Klekovkin. Use of The Interactive Mathematical System Geogebra When Teaching Differential Geometry. Spatial Curves. In: Bulletin of the Orenburg State Pedagogical University. Electronic scientific magazine, 4(32) (2019) pp. 257-284. 